\title{
THE MASTER OF DISTANCE EDUCATION PROGRAM: A COLLABORATION BETWEEN THE UNIVERSITY OF MARYLAND UNIVERSITY COLLEGE AND OLDENBURG UNIVERSITY
}

\author{
Eugene Rubin \\ Associate Vice President, Office of Instructional Development \\ University of Maryland University College \\ Email: erubin@umuc.edu \\ Ulrich Bernath \\ Director, Center for Distance Education \\ Carl von Ossietzky University of Oldenburg \\ D - 26111 Oldenburg \\ Germany \\ Tel: +49 4417984415 \\ Fax: + 494417984414 \\ E-mail: ulrich.bernath@uni-oldenburg.de \\ Mark Parker \\ Executive Assistant to the Provost \\ University of Maryland University College \\ Email: mparker@umuc.edu
}

\begin{abstract}
On November 15, 2003, The Master of Distance Education (MDE) program at the University of Maryland University College (UMUC) received the 2003 Sloan-C award for Most Outstanding Online Teaching and Learning Program. This award was given to the MDE "for an asynchronous, studentcentered online graduate program that responds to the worldwide need for qualified managers of distance education programs in industry and academe." This paper provides information about the program, the partnership and the curriculum.
\end{abstract}

\section{KEYWORDS}

Online education, professional development, partnership, distance education

\section{BACKGROUND}

The program grew out of a collaboration between Eugene Rubin from UMUC and Ulrich Bernath of Carl von Ossietzky University of Oldenburg, located in northern Germany. These two distance educators felt that there was a significant need for professional training in the field. In the midst of an institutional rush 
toward distance education, they felt that some crucial issues are in danger of being forgotten. There are very few formal opportunities for faculty and professionals in higher educational institutions, government and industry to develop knowledge of and skills in distance education. While there are a very small number of degree or certificate programs in the field of distance education, most are not easily accessible. Several institutions which offer distance education also offer faculty development programs, but these do not have formal recognition and often relate to specific technologies and skills. Distance educators often end up learning how to develop and deliver courses through the trial and error method (getting occasional advice from their more experienced colleagues.) In fact, this is true of the vast majority of University faculty, distance or otherwise! They do this with almost no background in distance education theory, pedagogical models, or positive examples of good practice.

It was felt that there are two critical needs that emerge from this analysis:

- There is a need for a training program in which new distance educators can develop a broader perspective of the general foundations of distance education and can learn critical knowledge and skills in the field.

- There is also a need for a global perspective among distance educators so that they can benefit from the knowledge of how other institutions approach distance education and solve problems, particularly in cross-border and cross-cultural contexts.

Given that need for faculty development and training in distance education, the authors submitted a proposal in 1995 to participate in the "Global Distance Learning Initiative" of the International Council for Distance Education (ICDE), who, in collaboration with the AT\&T Foundation, offered a series of grants for research/exploration in the area of distance education. They were awarded a grant for 1996/97.

The objective of this project for professional development in distance education was to develop a 10week course entitled "A Virtual Seminar for University Faculty and Administrators: Professional Development in Distance Education”.

The core professional development strategy of the Seminar is one of combining the idea of master practitioner with that of peer interaction. Each part of the syllabus was achieved by common discussion of a topic supported by interaction with a well qualified expert in the field of distance education. Thus, the design of the Seminar was one of a meeting of peers and not one of a relationship between students and teacher. The Seminar feature of visiting experts was a unique opportunity to interact (in almost real-time) with distinguished scholars and practitioners. It was reasoned that it would be a strong motivator for faculty to persist in the Seminar, since this opportunity would not normally be available elsewhere.

The Seminar Leaders were well aware that they were dealing with qualified professionals who were actively employed in academia, business or government. We were also aware that many of the academics were engaged in a regular teaching calendar. In other words, the participants were a group of working professionals who had commitments other than the Seminar. The Seminar Leaders jointly provided the overall frame for each of the weekly discussions. Both Seminar Leaders had a wide variety of experiences in distance education to share with the participants.

The syllabus for the first Seminar in 1997 was as follows:

Week 1: Introduction and practice with the conferencing system

Week 2: Foundations of Distance Education — with guest expert Börje Holmberg 
Week 3: Institutional Models of Distance Education — with Gary Miller

Week 4: Theories of Distance Education — with Otto Peters

Week 5: Technology of Distance Education — with Tony Bates

Week 6: Orientation into Distance Education Applications and Project Planning

Week 7: Student Support and Assessment

Week 8: Instructional Design and Course Development

Week 9: Technology Applications

Week 10: Project Reports, Summary and Conclusion

The Virtual Seminar was a success. The global aspect of the seminar was also important for its success. By being globally accessible via the Internet, the content and interaction allowed participants to generalize across cultural borders and among the diverse practices within the field of distance education. It gave depth to the learning and forced the participants to think beyond their own cultural and environmental constraints.

The seminar was also an example of distance education in practice. One of the primary goals of the seminar was to inform distance educators about issues related to the practice of distance education. We essentially "practiced what we preached." It even allowed some of the more experienced participants to obtain a better understanding of their own student's experience within distance courses.

The seminar was thoroughly evaluated and the results are well documented elsewhere (Bernath and Rubin) and the reader can find additional details there.

One of the more interesting outcomes of the virtual seminar was the joint decision of the two Seminar Leaders and their respective institutions to pursue the design, development and delivery of a Master of Distance Education degree. This decision came directly from the original intent to develop a means to train faculty and administrators in the area of distance education. While pursuing this goal, the Seminar Leaders began to see that, in fact, there was a broad range of content and skills that needed to be addressed, and that there was a serious need for more comprehensive education/training for those who manage and direct the distance education enterprise.

There are other similar Masters program; for example, the Open University of the U.K., Athabasca University in Canada and the University of Southern Queensland in Australia, but it was apparent to the authors that the demand for such training was rapidly increasing and the providers were few and far between.

It is the first course on Foundations of Distance Education in the new Masters program that is the direct evolution of the Virtual Seminar, and the syllabus and teaching methods of this first course was directly based on the syllabus and methods of the Virtual Seminar. As it stands, the Virtual Seminar is an ideal model for a broad look at distance education and would serve as an effective introduction to the field for beginning graduate students. For us, the Seminar Leaders, this was the perfect logical outcome of the Virtual Seminar.

\section{DETAILED DESCRIPTION OF THE MASTERS PROGRAM}

University of Maryland University College and Carl von Ossietzky University of Oldenburg's 
asynchronous online Master of Distance Education program is designed for students who are, or intend to be, involved in the distance education enterprise within the educational, business, government, and notfor-profit sectors. In a rapidly expanding and evolving field, graduates of the MDE are prepared to engage in the planning, design, implementation, delivery, and support of distance education and distance training programs. Having offered its first course in Spring 2000, the MDE has grown to a global student body of more than 300 students representing 38 different states and 12 nations. The fully online program is delivered asynchronously via WebTycho, UMUC’s proprietary web-based platform for course delivery.

The MDE is a graduate program that not only exemplifies the core characteristics of asynchronous learning networks (ALNs) but is also centered on ALNs and related distance education concepts in terms of the academic content of the program. Through their experiences in the MDE, students learn to critically examine the design and delivery of ALNs and other distance learning programs from a variety of perspectives - as students, consumers, managers, planners, teachers, and scholars. Likewise, the program challenges students to critically engage in the field of distance education in the following ways:

a. Understand and critique the broader policy, regulatory, and social issues that arise from distance education;

b. Plan and manage distance-based courses, programs, departments, and organizations;

c. Design, develop, and deliver high-quality programs that reflect a variety of effective approaches to teaching and learning;

d. Examine what it means to engage in distance and technology-mediated learning from a learner's perspective;

e. Select and implement technologies on the basis of their educational effectiveness and operational characteristics;

f. Conduct and evaluate research in the field; and

g. Cost and budget distance education delivery systems

\section{PROGRAM PARTNERSHIP}

One of the eleven institutions constituting the University System of Maryland, UMUC was founded in 1947 with the special mission of providing access to higher education opportunities for adult students. During FY 2002, UMUC's student headcount surpassed 85,000 worldwide. In that same year, worldwide enrollments in online courses reached 107,000. The Graduate School currently offers 17 master's degrees (all of which are available fully online), a doctoral degree program, and more than 35 graduate certificates. Fields of study are concentrated in the areas of business and management, technology, and education. In many respects, the discipline of distance education represents the synthesis of these three fields and draws upon existing areas of institutional strength. As one of the benchmark leaders in online education, UMUC is well positioned to offer a program with this particular focus and to share its expertise and experiences with the larger academic community.

The Carl von Ossietzky University of Oldenburg is one of the youngest universities in Germany. Founded in 1973, the institution evolved from the city's 200-year-old teacher training college. Today, the university has grown to include academic departments such as the Social Sciences, Arts and Humanities, Education, Economics, Languages, Mathematics, Natural Sciences, and Computer Science. Approximately 10,500 students are currently enrolled in more than 30 courses of study. Oldenburg's Center for Distance Education, founded in 1978, is a central unit of the university. It is a leading center in German distance education and particularly in the development of asynchronous learning networks with an emphasis on online tutorials and seminars. 
The Arbeitsstelle Fernstudienforschung (ASF), or Center for Research in Distance Education, a joint unit of the Center for Distance Education and the School of Education of Carl von Ossietzky University of Oldenburg, Germany, supports inquiry in light of relevant international research in distance education and facilitates the development of distance learning programs and courses within the university as well as in a national and international context. Dr. Ulrich Bernath, Director, and other Oldenburg faculty collaborate with UMUC in areas such as course development for the MDE, teaching, and recruitment of external content experts for advice, consultation, and participation in the program. Oldenburg University also contributes two post-baccalaureate certificate programs within the MDE: "Foundations of Distance Education" and "Distance Education in Developing Countries." One of the remarkable outcomes of the collaboration between Oldenburg University and UMUC is that the ASF Series now provides a series of volumes that directly support specific MDE courses as well as contribute to the overall scholarship in the field of distance education.

\section{PROGRAM CURRICULUM}

The 36-credit MDE curriculum consists of 7 core courses and 4 elective courses, with the additional requirement of a final integrative project. The MDE curriculum is intentionally structured to provide students with both breadth and depth in the field of study. When UMUC and Oldenburg faculty first joined together to design the program curriculum, they decided that an appropriate balance should be sought between the pedagogical, technological, and economic aspects of distance education, and the broader theoretical, historical, and social views of this field. In this respect, the program curriculum seeks to position the evolving role of distance education within a larger societal framework. Whereas many related graduate-level programs may focus more narrowly on instructional design and development, educational technology, or administrative and management issues, the MDE takes a more multidisciplinary approach by seeking to integrate each of these subject areas. Indeed, as the program has matured, it has moved closer to a focus on leadership, which requires such a multidisciplinary approach.

MDE courses are structured as graduate-level online seminars in which students and faculty are immersed in the literature, research, and scholarship from major contributors in the field of distance education. Students are challenged to critically analyze the concepts and issues they encounter in their readings and to apply their own professional experiences in their class discussions. Several MDE courses have also incorporated the "visiting experts" model, designed to bring distance education scholars into the classroom to facilitate modules or short-term discussions (this concept will be explained in further detail under "Contributions to Research and Scholarship" below).

Syllabi for 17 MDE courses that have already been developed in the program are available at the following URL address: http://www.info.umuc.edu/mde. Additional courses are still under development.

The MDE program curriculum is structured as follows (all courses are three credits):

\section{Core Courses (required):}

\section{OMDE 601 Foundations of Distance Education}

The goal of the course is to provide students with a foundation of the knowledge, skills, and attitudes that are required by a competent practitioner of distance education. Students explore the critical concepts and issues identified in the distance education literature and critically examine the history and theories of the field. The course was developed by Ulrich Bernath (Germany) and Eugene Rubin (U.S.) in collaboration 
with Börje Holmberg (Sweden) and Otto Peters (Germany). This course must be taken in the first term the student is enrolled in the program. It is taught in multiple sections by a team of faculty with Michael Beaudoin (U.S.), Ulrich Bernath, Thomas Hülsmann (Germany), Christine Walti (Germany/U.S.) and visiting experts Börje Holmberg (Germany/Sweden), Otto Peters (Germany), and Michael Moore (U.S.).

\section{OMDE 602 Distance Education Systems}

The functions of distance education within the organizational structure of educational institutions, businesses, non-profit organizations and government are examined. Students analyze operational, logistic, and regulatory systems within distance education and training organizations. A range of theories pertaining to systems in general, systems in education, systems needs in distance education, and systems approaches to organizational development are introduced. This course was developed by Eugene Rubin, and is presently taught by Yolanda Gayol (U.S./Mexico).

\section{OMDE 603 Technology in Distance Education}

This course explores the role of technology in the design, development, and delivery of distance education. Students critically examine the relationship between technology and the goals of the educational/training organization. Various uses of technology are explored in the areas of course development, asynchronous and synchronous distance course delivery, and management/administration. The relationship of information technology and distance education is explored, and special emphasis is placed on computer-based technologies. This course was developed and is taught by Judy Roberts (Canada).

\section{OMDE 606 The Management of Distance Education 1: Cost Analysis}

The course places the economics of distance education in the larger context of economics of education. A variety of methodological approaches (including cost/benefit and cost/effectiveness analysis) are applied to the distance education context. A variety of costing techniques and economic models are explored and applied to different institutional forms and levels of distance education. This course was developed by Thomas Hülsmann. It is taught by Thomas Hülsmann with visiting experts Greville Rumble (U.K.) and Tony Bates (Canada). The title of this course was changed in Spring 2003. Before that it was OMDE 606 Economics of Distance Education.

\section{OMDE 604 The Management of Distance Education 2: Leadership in D.E.}

This course introduces students to the organization, management, and administration of distance education systems. Specific issues include roles (both traditional and unique), leadership, human resource management, employee relations, the role of information technology, student support services, faculty/staff development, inter-institutional collaboration, funding, delivery systems, and policy. Both the education and business environments are explored in this course, and students gains an understanding and skills that allow them to function effectively in either type of organization. This course was developed and is taught by Eugene Rubin and Jim Gelatt (U.S.).

\section{OMDE 607 Instructional Design and Course Development in Distance Education}

This course examines the process of instructional design and development in a distance education and training context. Students critically evaluate the relationship between instructional design and technology. Various models of instructional and course development are considered (e.g., large vs. small scale course development, centralized vs. decentralized course development, individual faculty/author vs. team course development). Students apply the instructional development process by developing a small instructional unit. Special emphasis is given to web-based instructional design and delivery. This course was developed 
by Eugene Rubin and Inez Giles (U.S.). Beginning in Fall of 2002 this course is taught by Som Naidu (Australia).

\section{OMDE 608 Student Support in Distance Education and Training}

This course focuses on planning and management of learner support and interaction within modern distance education and training systems. Included are all types of tutorial and instructional assistance (mentoring, tutoring, teaching), advising and counseling services, library, and administrative services (admissions, registration, prior learning assistance, credit coordination, help desk). In this context, students explore topics such as learner retention, the role of evaluation and applied research, serving learners with special needs, and practitioners' professional development, and develop an understanding of contextual factors that determine the choice of particular learner support models. In the final course unit, students work in teams to custom design learner support services for an educational or training provider. The course was developed by Jane Brindley (Canada) and Alan Tait (U.K.) and is taught by Jane Brindley and Christine Walti. This course was OMDE624 until Spring 2002.

\section{Electives (students choose four):}

\section{OMDE 611 Issues in the Delivery of Library Services to Distance Students}

An overview of the design and delivery of library services and education to distance education students is provided. The course reviews the types of distance technologies used and how the library can be integrated into the delivery of courses in a variety of formats. In addition, this course covers methods for developing and evaluating library instructional materials, primarily in web-based formats, to teach distance education students library research skills. This course was developed and is taught by Ilene Frank (U.S.).

\section{OMDE 614 Intellectual Property and Copyright}

This course provides an overview of intellectual property issues that impact digital distance education. As both creators and users of copyrighted information, educators are affected by the rules surrounding ownership and use of information. Most distance educators are not aware of the implications of copyright law and digital delivery of materials and make preventable mistakes. This course gives educators a general framework for addressing issues such as ownership of electronic course materials, determining whether a work is in the public domain, proper use of copyrighted works at a distance and licensing mechanisms and processes. Prevention of plagiarism in the digital environment is also addressed. Finally, participants will discuss whether recent legislation that has amended the Copyright Act of 1976 achieves the goal of advancing knowledge and learning. This course was developed and is taught by Kim Bonner (U.S.).

\section{OMDE 620 Learning and Teaching with Multimedia}

This course focuses on the design and evaluation of multimedia learning and teaching environments in higher education settings as well as corporate training contexts. Multimedia is broadly defined as learning from verbal and visual material. Students are introduced to principles of multimedia design based on cognitive theories and constructivist approaches to learning. Pedagogical aspects of technological innovations in distance education, promises and pitfalls of multimedia learning, media selection, and computer- supported collaborative work (CSCW) will also be addressed. Students explore the characteristics, possibilities and limits of various multimedia products, develop criteria for their evaluation and design their own concept for a multimedia project. The course was taught (up to Spring 2003) by Joachim Hasebrook (Germany) as OMDE 605 and was redesigned and is taught by Hilko Donker and Olaf Zawacki (Germany). 


\section{OMDE 621 Training at a Distance}

This course examines the role of distance training in business, non-profit, and government organizations. Students explore a wide variety of issues, problems, and solutions in the areas of: web-based training, the economics of distance training, distance technology in the business organization, synchronous vs. asynchronous interactive tools, collaborative and problem solving tools, authoring tools, insourcing vs. outsourcing, and the role of multimedia in distance training. Specific emphasis is given to the concept of the Corporate Virtual University and its design and operation. This course was developed and is taught by Greg Kearsley (U.S.).

\section{OMDE 622 The Business of Distance Education}

Distance Education/Training is emerging within a highly competitive environment. Not only does the manager need to know about cost effectiveness issues, but he/she also is often responsible for such issues as marketing (local, national, and, increasingly, world-wide), insourcing vs. outsourcing, balancing the strong entrepreneurial focus of distance education within more traditional service-based organizations, and whether the distance education unit should be integrated or self-supporting. The course includes emphasis on the development of business and marketing plans and the use of common business analysis tools. In addition, students explore the rapidly expanding role of private and publicly traded education companies that are marketing new distance education products and services to the consumer market. This course was developed and is taught by Eugene Rubin (U.S.).

\section{OMDE 623 Web-Based Learning and Teaching and The Virtual University}

The Virtual University is a new concept that has recently evolved as a result of the emergence of the World Wide Web as a means of delivering higher education. This course covers the brief history, definitions, and implementations of the concept of the Virtual University in higher education, government and business. The rapidly evolving literature of web-based learning is explored, with special emphasis placed on web-based pedagogy and course design. In addition, the impact of web-based technologies is discussed. Students begin developing web-based learning environments and use web-based communication tools. This course was developed and is taught by Yolanda Gayol (Mexico/U.S.).

\section{OMDE 625 National and International Policies for Distance Education in Developing Countries}

This course is an exercise in stocktaking. It examines the purposes for which distance education has been used and the audiences reached. It analyzes the roles played by international agencies including bilateral and multilateral funding agencies, the UN family, regional bodies, and specialist agencies. The goal of the course is to develop and use typologies in order to examine the advantages and disadvantages of a range of organizational models for distance education at various educational levels, relating to audience, educational purpose, and choice of technologies. This course was developed and is taught by Thomas Hülsmann in collaboration with Hilary Perraton (U.K.).

\section{OMDE 626 Technologies for Distance Education in Developing Countries}

This course is explorative in character. It examines the range of educational technologies that assist institutions in reaching various off-campus audiences (from print, through broadcasting to satellite links and computer-based systems). The course examines the use of computers in school for (a) information science and computer studies (b) application to the general curriculum (c) access to internet (d) school linking. It gives an assessment of current and planned ventures including emerging rich-country policies and institutions, the changing role of the private sector, the role of conventional universities in relation to e-learning and the new international players (e.g. African Virtual University). The course was developed by Thomas Hülsmann and beginning in Fall 2003 is taught in collaboration with Michael Moore (U.S.). 


\section{OMDE 631 Advanced Technology in DE I: Synchronous Learning Systems}

This is an advanced course that builds upon OMDE 603 Technology in Distance Education. The course focuses on synchronous (real time) technologies that are used for DE such as satellite broadcasting, cable channels (CATV), telephony, wireless technology (WAP), web-based technological such as push, pull, compression, and streaming. Also, students are introduced to synchronous tools such as MOOs, MUDs, ICQ, text and audio chat, 2D-3D, application sharing, and white board. Students critically examine instructional-led learning environments and audio and video systems such as: interactive TV, site-based videoconference, and desktop videoconference. Technical details regarding standards-based technologies, telecommunications technologies, and computer technologies are also examined so students will be able to effectively manage the implementation of these tools. This course was developed and is taught by Gila Kurtz (Israel).

\section{OMDE 632 Advanced Technology in DE II: Asynchronous Learning Systems}

This is an advanced course that builds upon OMDE 603 Technology in Distance Education. The course focuses specifically on asynchronous (non-real time) technologies such as computer-mediated communication (computer conferencing), e-mail, listserves, archived streaming audio and video, etc. Technical details are covered relating to telecommunications technologies, video technologies, and computer technologies to ensure that the students can effectively manage the technical implementation of these tools. This course was developed and is taught by Robert Sapp (U.S.).

\section{Capstone (required):}

\section{OMDE 690 Distance Education Portfolio and Project}

This capstone course requires students to engage in two significant tasks: (1) create a personal distance education portfolio to serve as an ongoing professional resource, as well as a useful job search tool, and (2) develop and document a case study/project for an organization in the area of distance education and training. The purpose of this course is to provide students with an opportunity to display and practice a variety of skills and knowledge in the area of distance education and training. This course is taught by Eugene Rubin, Michael Beaudoin, and Ulrich Bernath.

\section{MDE Graduate Certificate Programs:}

One of the unique features of the MDE program is that students can pursue one of six graduate certificates in distance education in addition to, or instead of, the master's degree. These certificate programs are ideal for students who want to gain expertise in a particular content area related to distance education but may not want to commit to the entire degree program. Students may also choose to earn certificates en route to the degree program and can apply the appropriate credits in their entirety: 


\section{Foundations of Distance Education}

Total Semester Hours: 12

\section{$\underline{\text { Required Courses }}$}

- OMDE 601 Foundations of Distance Education

- OMDE 606 The Management of Distance Education 1: Cost Analysis

- OMDE 608 Student Support in Distance Education and Training

- OMDE 620 Learning and Teaching with Multimedia

\section{Distance Education and Technology}

Total Semester Hours: 12

$\underline{\text { Required Courses }}$

- OMDE 601 Foundations of Distance Education

- OMDE 603 Technology in Distance Education

Elective Courses (choose two)

- OMDE 620 Learning and Teaching with Multimedia

- OMDE 623 Web-Based Learning and Teaching and the Virtual University

- OMDE 631 Advanced Technology in Distance Education I: Synchronous Systems

- OMDE 632 Advanced Technology in Distance Education II: Asynchronous Systems

\section{Library Services in Distance Education}

Total Semester Hours: 12

$\underline{\text { Required Courses }}$

- OMDE 601 Foundations of Distance Education

- OMDE 603 Technology in Distance Education

- OMDE 611 Issues in the Delivery of Library Services to Distance Students

\section{Elective Courses}

- Students may choose one course from among the elective courses in the Master of Distance Education program.

\section{Teaching at a Distance}

Total Semester Hours: 12

$\underline{\text { Required Courses }}$

- OMDE 601 Foundations of Distance Education

- OMDE 603 Technology in Distance Education

- OMDE 607 Instructional Design and Course Development in D.E.

- OMDE 623 Web-Based Learning and Teaching and the Virtual University 


\section{Training at a Distance}

Total Semester Hours: 12

$\underline{\text { Required Courses }}$

- OMDE 601 Foundations of Distance Education

- OMDE 621 Training at a Distance

- OMDE 622 The Business of Distance Education

\section{Elective Courses}

- Students may choose one course from among the elective courses in the Master of Distance Education program.

\section{Distance Education in Developing Countries}

Total Semester Hours: 12

\section{$\underline{\text { Required Courses }}$}

- OMDE 601 Foundations of Distance Education

- OMDE 606 The Management of Distance Education 1: Cost Analysis

- OMDE 625 National and International Policies for Distance Education in Developing Countries

- OMDE 626 Technologies for Distance Education in Developing Countries

\section{URLS FOR PROGRAM MATERIALS}

Master of Distance Education Home Pages

UMUC: http://info.umuc.edu/mde/

Oldenburg: http://www.uni-oldenburg.de/zef/mde/info/

Features include general program information, advising resources, sample course syllabi, links to external distance education resources (research and professional), student discussion area, and faculty/staff directory.

Program Information in UMUC’s Graduate Catalog

http://www.umuc.edu/prog/gsmt/mde

WebTycho Tour and Online Orientation

http://www.umuc.edu/distance/de orien

Provides a user tour and overview of UMUC's online platform for course delivery, WebTycho.

University of Maryland University College Home Page

http://www.umuc.edu

Oldenburg University’s Center for Research in Distance Education Home Page (English Version) http://www.uni-oldenburg.de/zef/mde/ 


\section{DOCUMENTATION OF PROGRAM SUCCESS}

\section{A. Extending Access}

By offering the MDE fully online, and requiring only minimal levels of technology in terms of software and internet connectivity in order to participate, UMUC and Oldenburg provide the highest level of access currently possible for asynchronous programs. Evidence of this access is found in the geographic distribution of current students: approximately $40 \%$ of students enrolled in the MDE are Maryland residents, and the remainder represent 38 other states and 12 nations. As one of the very few graduate programs of its type in the world, the MDE provides an unprecedented opportunity to professionals who want to pursue graduate-level work in this field. There are no comparable online or classroom-based programs in the State of Maryland or in this region.

The program has the added benefit of bridging the resources, faculty, and expertise of two partnering higher education institutions in an international context. Most graduate students in U.S. programs do not have opportunities for exposure to broader perspectives provided through courses from two different universities.

As of Spring 2003 the program has awarded over 140 Certificates of Distance Education (a graduate certificate is defined as a minimum of 12 graduate credit hours by the Maryland Higher Education Commission) as well as $42 \mathrm{MDE}$ degrees. The flexibility to pursue a certificate rather than a full degree appeals to some students, particularly those with prior graduate degrees. Interestingly, many of the certificates have been awarded to degree-seeking MDE students. It appears such students specifically value the certificates as benchmarks of progress through the program; many have commented that the certificates help to keep career goals in focus and to maintain degree completion goals.

The asynchronous format of the MDE program itself lends to the recruitment of a diverse student body in terms of geographic location, career field, academic background, and professional aspirations. MDE students work in sectors such as small businesses, corporations, government agencies, not-for-profit organizations, colleges and universities, K-12 schools, and the military. The program has proven to appeal to students in diverse fields and at different stages in their careers. While many students have had extensive experiences in the field of distance education, others are looking to move into this field. Many students are working in organizations that could be described as "virtual" in focus, while others are in organizations that have begun to use technology more recently.

UMUC surrounds all of its fully online programs, including the MDE, with an array of technologymeditated support services for "distant” students. For example, students throughout the world can obtain such services as admissions, registration, financial aid, academic advising, career planning, and veterans and disabled student services through a variety of technologies. Of particular importance is UMUC's Office of Information \& Library Services (ILS), which provides access to library resources and services through both the online information system of the University System of Maryland and the World Wide Web. ILS also offers interlibrary loan options nationwide for all reference materials and worldwide for journal articles. There are more than $120 \mathrm{Web}$-accessible databases of which over half are full-text; these databases cover business, management, computer science, and a wide variety of other academic areas. ILS provides a book delivery service that ships USM books directly to students' homes in the U.S. and overseas, and is in the process of implementing access to digital books that allow users to retrieve and read entire texts online, and download and print selected sections of the text. 
In light of the characteristics of the MDE student population, UMUC and Oldenburg have recognized the importance of providing opportunities for professional networking and career development. In March 2001, for example, eight MDE students were funded by Nokia to attend a Mobile Learning Workshop held at Oldenburg. This event was part of pre-conference workshops to the $20^{\text {th }}$ ICDE World Conference in Germany, where another workshop provided participants with the opportunity to review the first year of the MDE program. Presentations were given by MDE faculty members Eugene Rubin, Ulrich Bernath, Jane Brindley, Thomas Hülsmann, and Michael Beaudoin, as well as distinguished faculty/experts Börje Holmberg and Otto Peters. In November 2000 and May 2002 at UMUC's campus in Adelphi, Maryland, and November 2002 in conjunction with the ALN Conference in Orlando well-attended get-togethers were held for MDE students and faculty. For most participating students, these get-togethers represented their first opportunity to meet their program colleagues and faculty members face-to-face. This year Volkswagen AutoUni (the corporate university of the Volkswagen Group) has agreed to sponsor five students to participate in the European Distance and E-Learning Network (EDEN) conference to be held in March, 2004 in Oldenburg.

\section{B. Contributions to Research and Scholarship}

In addition to providing critical opportunities for extending student access, the MDE program has also created a forum for furthering research and scholarship in the field of distance education. The asynchronous format of the program has made possible the creation of an international body of faculty members and visiting experts, including the following:

- Dr. Tony Bates, Director, Distance Education and Technology, Continuing Studies, University of British Columbia/Canada (Visiting Expert, OMDE 606)

- Dr. Michael Beaudoin, Professor of Education, University of New England/USA (Faculty, OMDE 601 and OMDE 690)

- Dr. Ulrich Bernath, Director, Center for Distance Education at Carl von Ossietzky University of Oldenburg/Germany (Faculty, OMDE 601 \& OMDE 690)

- Dr. Kim Bonner, Director, Center for Intellectual Property, UMUC (Faculty, OMDE 614)

- Dr. Jane Brindley, Intake Coordinator, Centre for Psychological Services, University of Windsor/Canada (Faculty, OMDE 608)

- Dr. Hilko Donker, Lecturer, University (TU) of Dresden/Germany (Faculty, OMDE 620)

- Eileen Frank, Reference Librarian, University of South Florida (Faculty, OMDE 611)

- Dr. Yolanda Gayol, Program Director, Master of Distance Education, University of Maryland University College/USA (Faculty, OMDE 602 \& OMDE 623)

- Dr. Inez Giles, University of Maryland University College (Faculty, OMDE 607)

- Dr. Joachim Hasebrook, President, efiport AG/Germany (Faculty, OMDE 620 until Spring 2002)

- Dr. Dr. h.c. Börje Holmberg, Former Rector, Private FernFachhochschule Darmstadt/Germany \& Professor Emeritus of Education, FernUniversität/Germany (Visiting Expert, OMDE 601)

- Thomas Hülsmann, Carl von Ossietzky University of Oldenburg/Germany (Faculty, OMDE 601, 606, 625, and 626)

- Dr. Greg Kearsley, Professor, Graduate School of Education and Human Development, George Washington University/USA (Faculty until 2003, OMDE 621)

- Dr. Michael Moore, Professor of Education, Founding Director of American Center for Study of Distance Education and Editor of American Journal of Distance Education, The Pennsylvania 
State University/USA (Visiting Expert, OMDE 601 and OMDE 626)

- Dr. Som Naidu, Assistant Professor, University of Melbourne/Australia, Editor, Distance Education. (Faculty, OMDE 607)

- Dr. Hilary Perraton, Former Director, International Research Foundation for Open and Distance Learning (IRFOL)/Cambridge UK (Visiting Expert, OMDE 625)

- Dr. Otto Peters, Professor Emeritus of Education, Founding Rector, FernUniversität Hagen/Germany (Visiting Expert, OMDE 601)

- Judy Roberts, President, Judy Roberts \& Associates/Associés, Inc/Toronto, Canada (Faculty, OMDE 603)

- Dr. Eugene Rubin, Program Chair, Master of Distance Education, University of Maryland University College/USA (Faculty, OMDE 601, 602, 604, 607, 622, 690)

- Dr. Greville Rumble, Professor, Open University/UK; Former Editor, Open Learning (Visiting Expert, OMDE 606)

- Christine Walti, Carl von Ossietzky University of Oldenburg/Germany (Faculty, OMDE 601 and OMDE 608)

- Olaf Zawacki, Carl von Ossietzky University of Oldenburg/Germany (Faculty, OMDE 620)

The "visiting experts" concept is designed to bring distance education scholars, researchers, and practitioners into the online classroom to facilitate a course module or short-term discussion on their topics of expertise. Students read books and articles written by their visiting experts and then have the opportunity to directly interact with them online in class. This approach is important not only in ensuring that the program curriculum is informed by the latest developments in the field, but also in helping students broaden their interests, understand the importance of research, and make theory-to-practice connections.

MDE faculty have been editors of internationally renowned journals in distance education, written articles and books in their respective areas of expertise, and received awards for their work in the field.

One of the more significant outcomes of the Master of Distance Education program has been the creation of a series of publications that directly support specific courses in the program, as well as contribute to the overall scholarship within the field of distance education. Oldenburg's Center for Research in Distance Education (Arbeitsstelle Fernstudienforschung or ASF) provides an edited series for the dissemination of research and scholarship primarily in the context of the MDE. The ASF Series (http://www.unioldenburg.de/zef/mde/series/) presently offers the following as required books in courses of the MDE:

- Vol. 2 (Thomas Hülsmann), The Cost of Open Learning: a Handbook. This handbook is designed to help educational managers use open and distance learning. It examines the comparative costs of various educational technologies based on eleven case studies from six European countries.

- Vol. 4 (Börje Holmberg, $2^{\text {nd }}$ ed.), Distance Education in Essence. An Overview of Theory and Practice in the Early Twenty-first Century. The author looks carefully into the character and applications of distance education, and presents a revised version of his much discussed overarching theory. Particular attention is paid to the innovatory character of distance education and the role of technology in today's practice, regarded as an auxiliary means that may serve educational purposes, not as important in itself.

- Vol. 5 (Otto Peters, $3^{\text {rd }}$ ed.), Distance Education in Transition. The author examines exciting changes and promising innovations in distance education which emerge as a result of far-reaching 
societal changes and spectacular advances of the information and communications technology. He widens and deepens his pedagogical approach to distance education and preserves the legacy of distance education in a new era. Experts as well as laymen will profit from reading this new publication as it deals with topical issues of the current development of distance education and online learning.

- Vol. 6 (Bernath \& Rubin (Eds.)), Reflections on Teaching and Learning in an Online Master Program - A Case Study. The book comprises thirteen articles contributed by the MDE program directors, faculty, and students from Canada, Germany, Sweden, and the U.S. The themes include institutional politics, program management, detailed cost analysis, student and faculty support, reflections on online and distance learners and learning behaviors, digital learning spaces, technologies, communication, facilitation, cooperation, and collaboration.

- Vol. 7 Greville Rumble (Ed.) Papers and Debates on the Economics and Costs of Distance and Online Learning

- Vol. 8 Michael Beaudoin Critical Issues in Distance Education Leadership (forthcoming 2004)

- Vol. 9 Jane Brindley, Christine Walti \& Olaf Zawacki-Richter (Eds.) Learner Support in Open, Distance and Online Learning Environments (forthcoming 2004)

- Vol. 10 Thomas Hülsmann \& Hilary Perraton (Eds.) Educational Technologies for Distance Education in Developing Countries (forthcoming 2004)

Additional faculty research initiatives include distance education cost analysis, student satisfaction, asynchronous communication processes and academic discourse, faculty support for online teaching, a "lifeworld" analysis of online students, and the concept of the invisible learner.

Despite their global dispersion, MDE faculty members have also had opportunities to meet with each other face-to-face for program planning, collaboration, and professional development. The first programwide faculty meeting was held in Frankfurt, Germany, in July 2000, and the second was held in Oldenburg, Germany, in March 2001 in conjunction with the $20^{\text {th }}$ ICDE World Conference. A third meeting for professional development was held in January 2002 in Oldenburg, and a fourth meeting was held in conjunction with the $8^{\text {th }}$ Sloan-C Conference in Orlando in November 2002. The most recent program-wide faculty meeting happened in conjunction with The Third EDEN Research Workshop on "Supporting the Learner in Distance Education and E-Learning" in Oldenburg, March 4 - 6, 2004.

\section{Student Satisfaction}

Since the initial implementation of the MDE program in Spring 2000, formal student feedback has been received for every course that has been offered (a total of 98 course sections with an average of 18 students per section as of Summer term 2003). Course evaluations are carefully monitored to measure student satisfaction with each course and to make adjustments as appropriate. For example, during the period Spring 2000 to Summer 2002 the foundation course OMDE 601 received a weighted mean overall rating of 4.17 out of a possible 5 on a Likert scale (the range of individual student ratings was 4.02 to 4.55). While this and similar student feedback has been positive, it has also provided UMUC and Oldenburg with ideas for improvement in specific courses. (See: Vol 6 of the ASF Series, pp. 32-40) Other avenues for student feedback have included additional questionnaires in selected courses, face-toface meetings with faculty (such as the meetings held in Oldenburg, Germany, Adelphi, Maryland, and Orlando), teleconferences, and a program-wide discussion forum. 
Additional student comments may be found in Vol 6 of the ASF Series, pp. 40-41.

\section{Learning Effectiveness}

UMUC and Oldenburg use a variety of measures to evaluate learning effectiveness. The MDE capstone course (OMDE 690) is one such measure designed to help assess what students have learned throughout the MDE program. This course provides an integrative learning experience in which students complete a major distance education project and finalize a personal distance education portfolio. The personal portfolio, which is a requirement for successful completion of the capstone course, contains both required and optional materials. Required materials are assignments and other contributions to the final grades in each course. Optional materials may highlight any other kind of active participation in the courses of the Master's program; they allow students to show their proficiency and skills as professional distance educators. To date, 42 graduates of the program have used this portfolio to effectively demonstrate the significant professional development resulting from the MDE program.

Other measures that can be considered in evaluating learning effectiveness are student assignments and assessments in individual courses. MDE students have already been challenged to demonstrate their mastery of course concepts and material through research papers, individual and group projects, and other types of written assignments, including the following:

- Researching and providing "expert consultant" recommendations for institutions moving into online training and development;

- Case study analyses, including institutions and organizations such as Athabasca University, The Open University, NextEd, Unext, and Universitas 21;

- Student-created case studies with an analysis of contexts, factors, resources, learners, challenges, and opportunities;

- Analyses of best practices in distance education;

- Creation of a context-specific distance education system with an analysis of each component and graphical representation of how the various components interact with each other;

- Application of decision-making criteria to choose appropriate technologies for particular learning goals/environments;

- "Memos to the President" related to a wide range of leadership and management issues in distance education; and

- Examination of critical issues faced by distance education managers in different functional areas (student services, course/instructional design, technology managers, etc.).

A specific example of success in this area comes from a current student who, for one of her assignments in the foundation course OMDE 601, was inspired to develop and actually implement a Distance Education Service \& Support Program (DESASP) for U.S. military personnel and their families stationed in remote areas of the United Kingdom. Not only did this student provide valuable services to a community of distance learners; she also learned important, sometimes hard lessons about establishing and running a not-for-profit, largely volunteer services organization. Of her experience she wrote, "The MDE program has given me the confidence to develop a program that has become an important part of this remote military community. It has taught me the importance of interaction in a learning environment, the importance of research, and project management, design and evaluation.” 
Recent graduates of the program also provide an important gauge not only of learning effectiveness but also of the MDE program's success in reaching its target audience. For instance, of the eight students who received the MDE in May 2003:

- One is a program director for the Curriculum Development Center at the Defense Acquisition University (DAU). She is responsible for the content of a suite of DAU courses and is in the process of converting some of them to Web-based delivery. She credits the MDE with having provided her "a better understanding of basic educational theories as well as how to manage the development of courses that will be taught via distance modes.”

- One is a government contractor working on the establishment of Web-based courses and a learning management system for the U.S. Department of Defense's Clinical Information Technology Program Office (CITPO). She recently gave what we consider the ultimate compliment when she wrote, "I have been able to use what I learned to make sure that the courses are delivered on time and within budget. I oversee the project from the customer's standpoint and ensure we are getting a quality product. I try to stay on top of what is happening in the distance learning field so that in the future we may add to our programs."

- One is a project manager for a distance learning/Web-based training program in the National Association of Student Financial Aid Administrators (NASFAA). The research she conducted on learning communities for her capstone project was not only directly applicable to her work at NASFAA but was also taken under consideration by the MDE directors in the review of the program itself.

- One is now a member of Oldenburg's faculty and a teacher in the MDE program. Her research focuses on learning journals and e-portfolios, and on communities of practice in the online environment. In addition, she has been asked by a Maryland community college to provide staff with "the basics" of putting courses and learning materials online.

If learning can be said to be effective when students are able to apply it not only in the classroom but also in the real world, then the above information suggests that the MDE program has a proven record of excellence in that endeavor.

\section{E. Related Outreach Activities}

Building on the model of the MDE, UMUC and Oldenburg have recently initiated several related outreach efforts in the field of distance education, including the following:

- From April through June 2001, Oldenburg’s Center for Distance Education in collaboration with UMUC provided a seven-week online course titled "Essentials of Online Learning” for Nokia (Finland) HRD staff using WebTycho. (See http://www.uni-oldenburg.de/zef/training/nokia.htm.) A second revised course took place October through November 2001. Evaluation results have been presented by Naidu \& Bernath on "Training the Trainers, Educators and other Human Resource Development Staff in the Essentials of Online Learning" on the Pan-Commonwealth Forum on Open Learning in Durban/South Africa, July 27-29, 2002

(See http://www.col.org/pcf2/papers/naidu_1.pdf.)

- The Global Development Learning Network of the World Bank has negotiated with Oldenburg's Center for Distance Education to offer a virtual seminar for professional development on "Distance Education in Developing Countries" in Fall 2002. The seminar for professional 
JALN Volume 8, Issue 3 - June 2004

development is closely connected with the content of OMDE 625 and OMDE 626 (http://www.uni-oldenburg.de/zef/english/DEiDC.htm).

\section{F. Cost Effectiveness}

There are several indicators that suggest the MDE constitutes a cost-effective approach to program delivery for both institutions. When the MDE program was first introduced in the Spring of 2000, UMUC already had in place a complete infrastructure designed to serve students and faculty at a distance and to support this scale of program development and delivery. This infrastructure included a complete array of online services ranging from admissions, financial aid, and registration, to student advising, an online bookstore, and library services. With its mission of educating adult part-time students, UMUC was already well equipped to meet the needs of new students in the MDE program without significant additional expenditures for these resources. Therefore, initial expenditures for the program would be largely confined to the areas of course development and faculty recruitment.

Today, UMUC and Oldenburg continue to pay special attention to issues of cost-effectiveness. Tana Bishop of UMUC and Thomas Hülsmann of Oldenburg are presently conducting a cost analysis study of the MDE program. Further, a case study on the Oldenburg portion of the MDE program on the costs of online learning has just been concluded by Hülsmann and the findings are now published in Vol. 6 of the above mentioned ASF series (http://www.uni-oldenburg.de/zef/cde/webvol6.pdf).

In its original MDE proposal to the Maryland Higher Education Commission UMUC projected a student headcount of 135 for Year III of the program (2003). In fact, the program now has more than 300 students worldwide. This tuition revenue stream, combined with UMUC's flexible course and faculty scheduling models, allows the two institutions to rapidly and efficiently add new sections of courses to accommodate increased demand.

\section{CONCLUSION}

The Master of Distance Education program addresses the growing critical need for managers and leaders of $\mathrm{DE}$ activities in all sectors of the economy. It successfully combines a scholarly approach to the discipline with praxis geared toward the realities of designing and managing DE programs in the workplace and in the academy. Because it is offered via ALN, the MDE is accessible to students throughout the U.S. and in many other nations. Indeed, the asynchronous online nature of the program facilitates one of its key features: a truly international faculty who provide students with a broad global context in which to study the pedagogical, technological, societal, and management-oriented aspects of distance education. The MDE exemplifies the promise ALNs hold for a new view of adult higher education: one that is global, student-centered, and dedicated to improving the human condition by providing opportunities for lifelong learning.

\section{ABOUT THE AUTHORS}

Eugene Rubin is Associate Vice President, Office of Instructional Development at the University of Maryland University College. He is also the Executive Director of the International University Consortium, which is a consortium of over 50 Universities world-wide which share in the development and use of distance education materials. As Chair of the Institute for Distance Education, he directs a University System of Maryland-wide organization to promote and develop distance education throughout the 15 member University of Maryland System. Prior to his appointment at University College, Dr. Rubin 
was at the Centre for Distance Education at Athabasca University in Canada, where he was a faculty member of a Masters in Distance Education program. He has a Ph.D. from the University of Michigan and a M.S. from Kansas State University. Dr. Rubin is the head of a 40 person course development unit which specializes in the development of distance education materials using a variety of instructional media, including print, video and computer multimedia. The unit is also responsible for support and training of faculty in the use of such technologies as computer conferencing, voicemail, interactive compressed video, and Internet/World Wide Web development.

Dr. Rubin has worked on educational, performance and training problems in a variety of environments: industry, government and academic. He has consulted with a variety of companies, owned his own company which developed contract training materials, and worked with several recognized performance and training consulting firms. He has run a variety of training workshops in the areas of Distance Education, Curriculum Design, Course Design and Development, Media, and the Management of Education and Training. He was also the Editor of the quarterly journal, Research in Distance Education.

Ulrich Bernath graduated in Economics in 1970 from Justus-Liebig University of Giessen/Germany and holds a Ph.D. in Education (Dr. phil.) from the School of Education at Carl von Ossietzky University of Oldenburg. In 2002, the University of Maryland University College (UMUC) has appointed Ulrich Bernath to their graduate faculty at the rank of Adjunct Professor.

Since 1978 he has been the Director of the Center for Distance Education at Oldenburg University. He was one of the founders of the European Study Centre Network North-West Germany (ESCN) and the

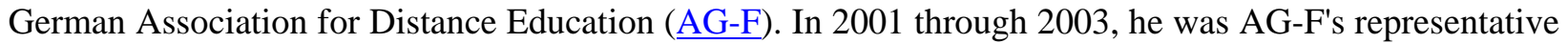
in the program committee of LEARNTEC.

Ulrich Bernath has been the Head of the Oldenburg Branch of the ICDE General Secretariat since 1995, responsible for Germany and the European Union. He serves as a member of the International Program Committees of the 18th through 21st ICDE World Conferences. In 2002, he became an elected member of the Steering Commitee of the European Distance and E-Learning Network (EDEN) for Academics and Professionals (NAP), and in 2003 he was elected as a member of EDEN's Executive Committee.

Ulrich Bernath was a visiting exchange scholar at Towson University, Maryland, in 1993/94, and designed the graduate course "Distance Education in Theory and Practice". In partnership with Dr. Eugene Rubin, University of Maryland University College (UMUC), he was granted by the AT\&T / ICDE "Global Distance Learning Initiative" in 1996/97 for the development of the virtual seminar for university faculty and administrators "Professional Development in Distance Education". Since 1999, both share their responsibilities as Program Directors for the online Master of Distance Education program, jointly offered by UMUC and Carl von Ossietzky University of Oldenburg. He is founding member of a joint initiative for "The Future of Learning \& Training", designing innovative settings and modes to enhance computer-supported collaborative learning and training.

Mark L. Parker is Executive Assistant to the Provost and Adjunct Assistant Professor, Graduate Studies at University of Maryland University College. In addition to his administrative duties he teaches an online expository writing course for new graduate students and is a member of the university's retention and research steering committees. 